\title{
Generation of Three-Dimensional Meteorological Field based on Sounding Data
}

\author{
Xuetao $\mathrm{Yu}^{1,2}$, Xiaoping Rui ${ }^{3,}$, Zhen Ding $^{4}$, Heming Sun ${ }^{5}$ and $\mathrm{Yi} \mathrm{Shu}^{6}$
}

\begin{abstract}
${ }^{1}$ Transportation Institute, Shijiazhuang Tiedao University, Shijiazhuang, Hebei, 050043, P.R. China, ${ }^{2}$ Traffic Safety and Control Lab in Hebei Province, Shijiazhuang, Hebei, 050043, P.R. China; ${ }^{3}$ College of Resources and Environment, University of Chinese Academy of Sciences, Beijing, 100049, P.R. China $;{ }^{4}$ The First Surveying and Mapping Institute of Anhui Province, Hefei, Anhui, 230031, P.R. China, ${ }^{5}$ School of Remote Sensing, Nanjing University of Information Science and Technology, Nanjing, Jiangsu, 210044, P.R. China; ${ }^{6}$ Quanzhou Meteorological Bureau, Quanzhou, Fujian, 362000, P.R. China
\end{abstract}

\begin{abstract}
Given the uneven distribution of sounding and automatic weather stations throughout the Fujian province of China, a method for the extension of meteorological elements from point data to a three dimensional field is proposed, which can be used for hail detection and other weather forecasts. Considering the temperature and air pressure as the classic meteorological elements, these are extended to two and three dimensions and the error is analyzed according to the spatial distribution law of temperature and air pressure in the horizontal and vertical directions. The conclusions are that (1) the extension method of the meteorological elements to two and three dimensions proposed in this paper is characterized by high precision and reliability and (2) the generated height map for the same temperature level and vertical cross section of temperature can be very helpful for hail and other weather forecasts.
\end{abstract}

Keywords: Meteorological elements, OpenGL, sounding data, three dimensional extension.

\section{INTRODUCTION}

Since the distribution of sounding and automatic weather stations is uneven, the time and place of hail shooting is uncertain and so is the formation height of hail stones above the $0^{\circ} \mathrm{C}$ level height. Therefore, the extension of point data from meteorological elements to a three-dimensional meteorological element field can provide precious data for hail detection and forecast. Fujian is a large province of complex terrain and varied climate, with an uneven distribution of weather stations. The establishment of a three-dimensional meteorological element field allows the full use of the meteorological data available for the study area. Spatial interpolation methods for meteorological elements have been studied extensively and widely. Studies include the interpolation of temperature, precipitation volume, and sunshine duration using inverse distance weighting, interpolating polynomials, spline, and kriging methods, among others. In addition, the differences between these methods have also been compared [1-9]. To estimate a 30-year period of 10-day mean air temperatures and monthly photosynthetic active radiation (PAR) fluxes at specific sites in China, Lin et al. applied the ordinary kriging (OK) and squares (IDS) and the gradient plus inverse-distance-squared (GIDS) [2]. The annual average and accumulated temperature and rainfall data from 2114 meteorological stations located in China and surrounding countries obtained in 1961-1990 were interpolated using inverse distance weighing (IDW), OK, and spline techniques with ArcMap by Ma et al. [6]. The three interpolation methods were evaluated by cross-validation and their results indicated that the precision of the interpolation varied significantly with the number of meteorological stations selected. Many researchers studied the two-dimensional extension of the distribution of meteorological elements, but did not consider a three-dimensional extension, in agreement with the three-dimensional spatial distribution of their characteristics. A meteorological element field in three dimensions can then more accurately describe the meteorological environment characteristics during hail or rainfall.

Assuming the Fujian province as a study area and considering the distribution characteristics of the meteorological elements in the horizontal and vertical directions, we proposed a method of establishing a meteorological element field in three dimensions and applied it using real sounding and automatic weather station data.

\section{METEOROLOGICAL DATA}

The selected meteorological data includes the meteorological element data generated every 10 minutes by automatic weather stations and the sounding data recorded daily at 8 a.m. and 8 p.m. The data from automatic weather stations can describe the surface meteorology while the sounding data can describe the meteorology at different heights. Given the limited number of sounding stations in China, to obtain the three-dimensional meteorological field for a large area, we selected six sounding stations (IDs 57933, 58633, $58725,58847,59134$, and 59316) located in or near the Fu- 


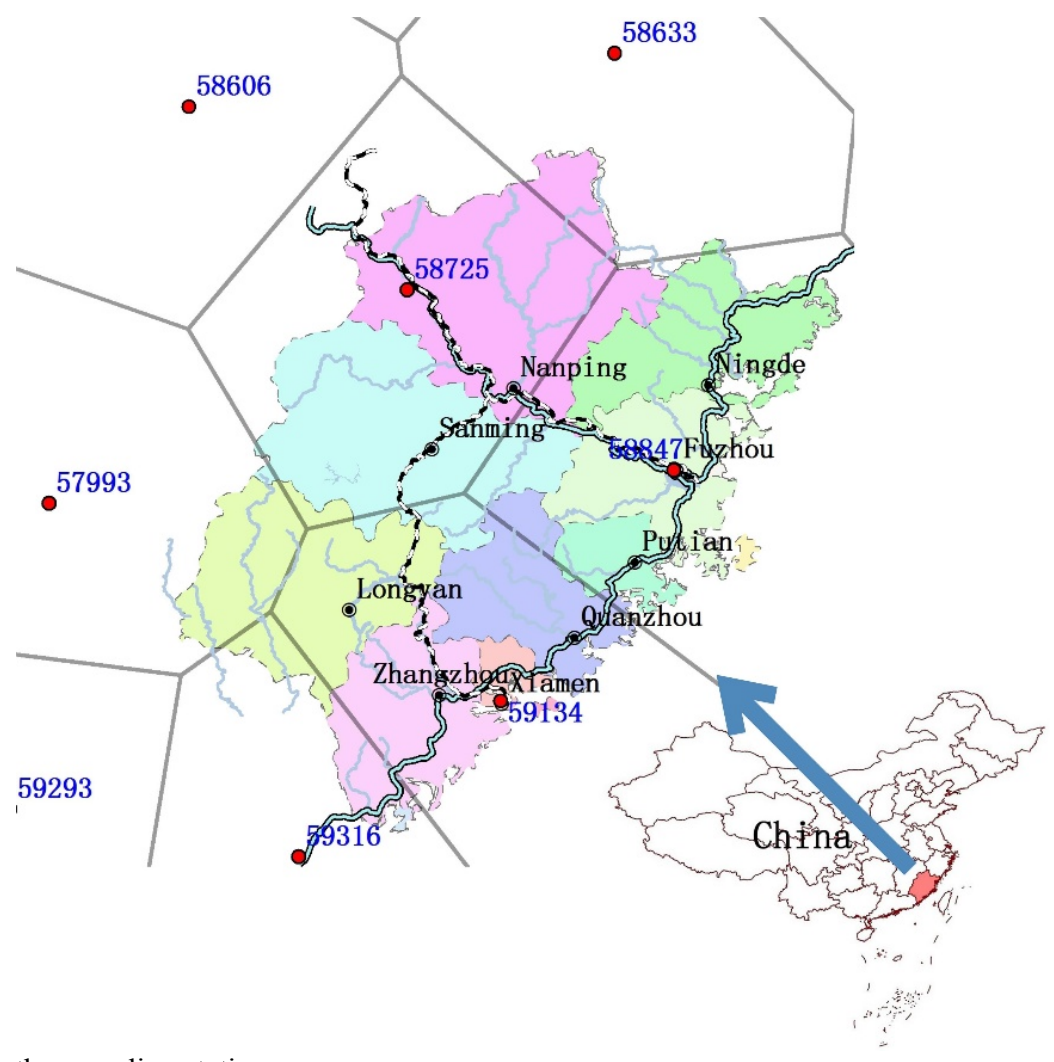

Fig. (1). Region coverage by the sounding stations.

jian province that could cover the entire province, as shown in Fig. (1).

\subsection{Meteorological Element Data from Automatic Weather Stations}

The data recorded at regular intervals by automatic weather stations includes the observation time (China Standard Time-CST), 2- and 10-minute average wind direction, 2- and 10-minute average wind speed, direction, occurrence time, and speed of the maximum wind, current wind speed and direction, current, minimum, and maximum temperature and their occurrence times, relative and minimum relative humidity and its occurrence time, vapor pressure, dew-point temperature, current, minimum, and maximum air pressure and their occurrence times, current, minimum, and maximum grass temperature and their occurrence times, current, minimum, and maximum surface temperature and their occurrence times, ground temperature below $5,10,15,20,40,80$, 160 , and $320 \mathrm{~cm}$, evaporation capacity, sea-level pressure, and current and minimum visibility and its occurrence time. The wind speed and direction, temperature, dew-point temperature, and air pressure are particularly useful for the understanding of the meteorological environment at a specific time.

\subsection{Sounding Data from Sounding Stations}

The sounding data includes aerial mapping and temperature $\log$ pressure $(\mathrm{T} \log \mathrm{P})$. The aerial mapping describes the meteorological element information for different surfaces of equal pressure $(1000,925,850,700,500,400,300,250$, 200,150 , and $100 \mathrm{hPa}$ ). The meteorological element information include the height above sea level, daily temperature, dew-point deficit, and wind speed and direction at 8 a.m. and 8 p.m. (CST). The TlogP sounding data includes the air pressure, height above sea level, temperature, dew-point temperature, and wind speed and direction, which is mainly used for generating the TlogP diagram in the MICAPS (Meteorological Information Comprehensive Analysis and Process System) software. The MICAPS software, developed by the China Meteorological Administration, is the main forecast operation system for processing satellite and radar weather data and numerical forecast products, being widely used in regional and provincial meteorological bureaus in China. Three versions have been developed, with the newest version MICAPS 4.0 officially launched in 2013.

\section{GENERATION METHODS}

As meteorological elements like temperature, moisture, and air pressure are usually presented as single-point data provided by automatic weather stations and their distribution is continuous, we could generate two-dimensional meteorological element fields using an efficient interpolation algorithm. In addition, given the clear changes in height for the air pressure and temperature and the possibility of acquiring meteorological values at different heights by the sounding stations, we could generate three-dimensional meteorological element fields combining multi-point sounding data and the two-dimensional meteorological element field.

The principle of spatial interpolation is to extend the value of the variables to the non-sampled grid points. Frequently used and widely known interpolation methods include the IDW, spline, kriging, and arithmetic mean. As these methods are mature algorithms in spatial interpolation, no more introduction and comments are made herein. Figs. (2) and (3) 


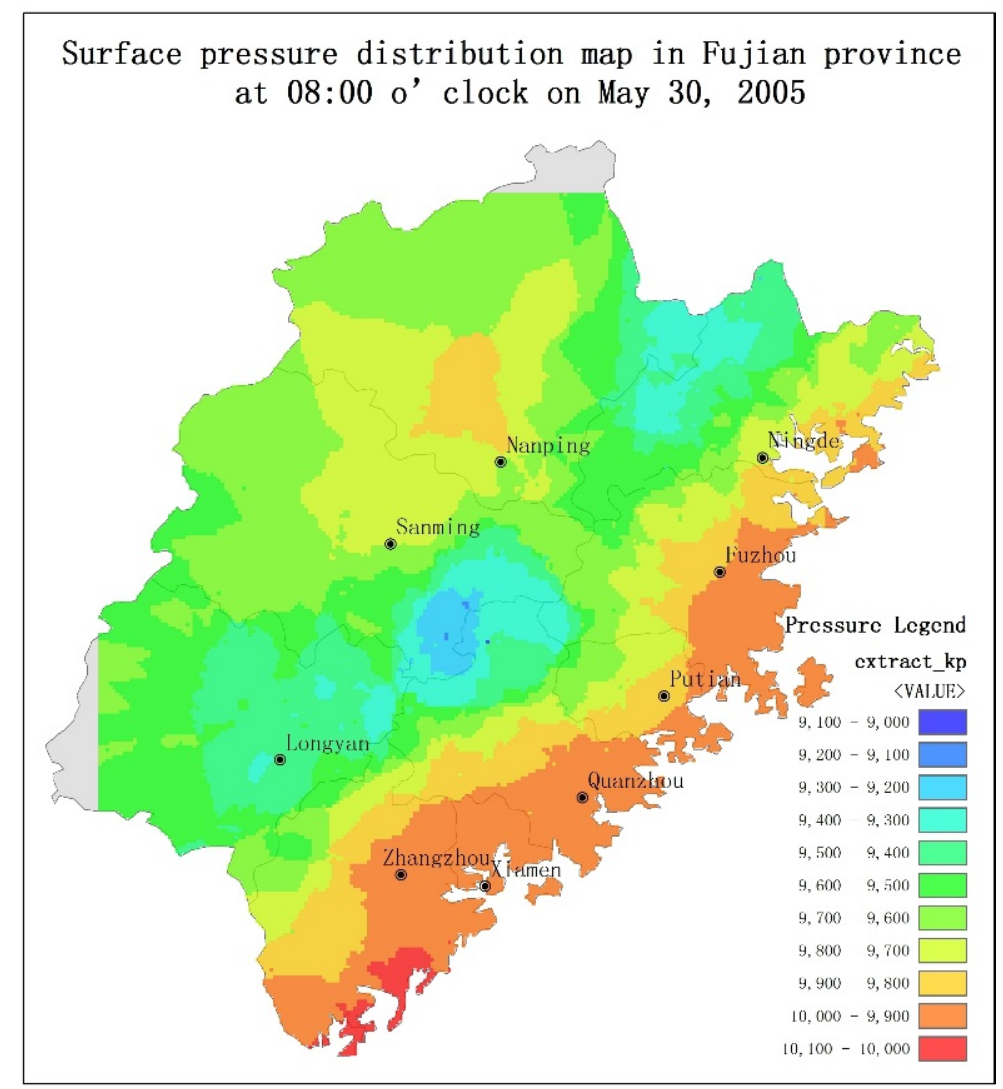

Fig. (2). Distribution map of surface air pressure (in hPa) for the Fujian province at 8 a.m. on May 30, 2005, using an ordinary kriging interpolation.

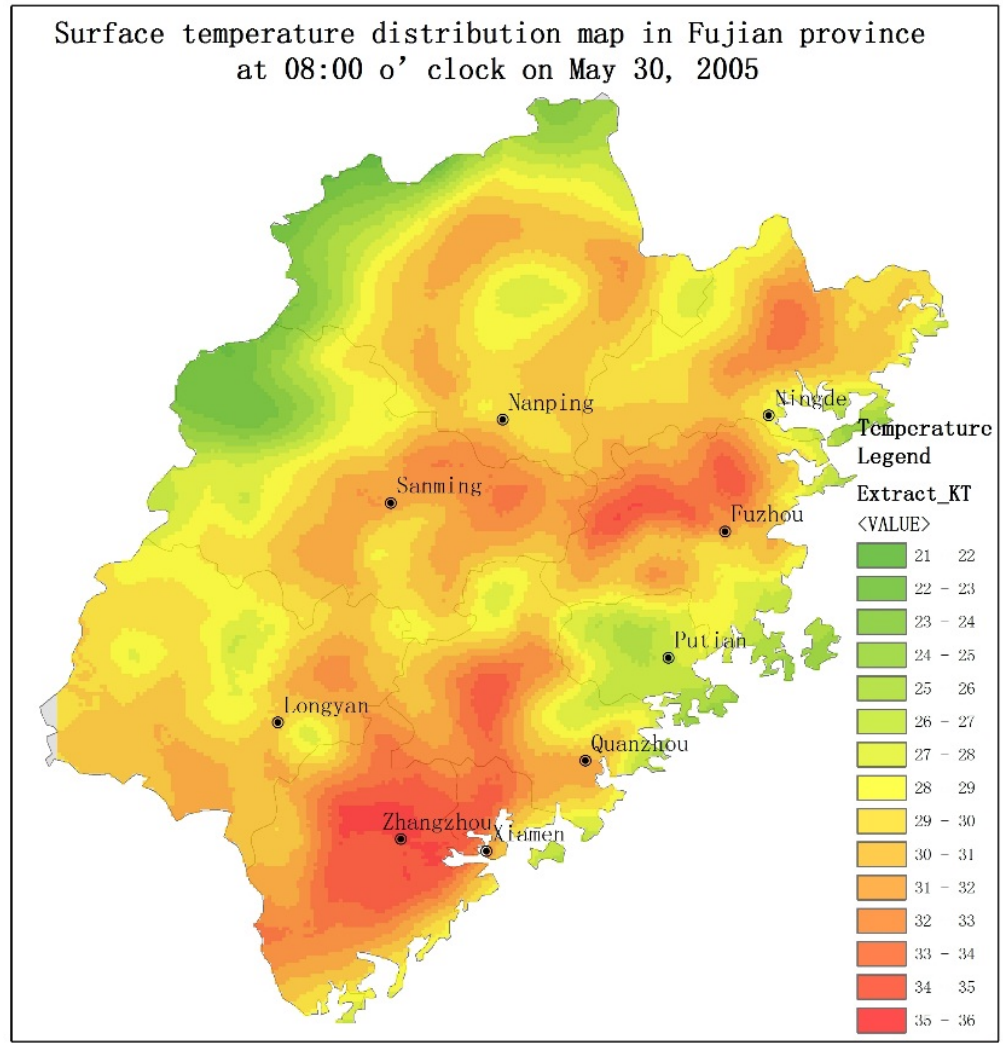

Fig. (3). Surface temperature distribution map $\left(\right.$ in $\left.^{\circ} \mathrm{C}\right)$ for the Fujian province at 8 a.m. on May 30, 2005, using an ordinary kriging interpolation. 

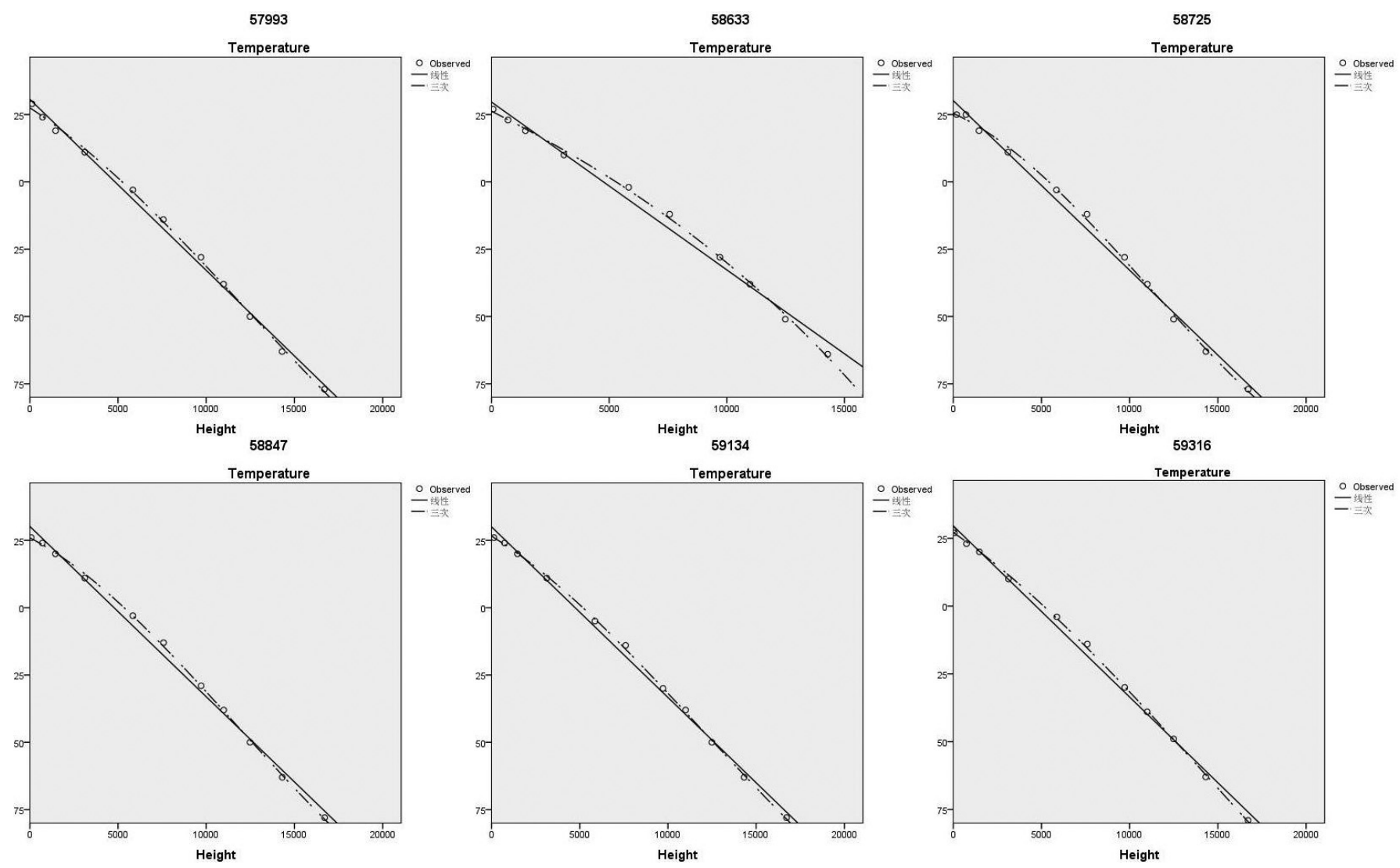

Fig. (4). Fitted temperature lines and curves according to the height.

Table 1. Parameters of the fitted temperature curves according to the height.

\begin{tabular}{|c|c|c|c|c|}
\hline Sounding Station & $\mathbf{c}$ & $\mathbf{x}$ & $\mathbf{x 2}$ & $\mathbf{x 3}$ \\
\hline \hline 57993 & 25.101 & $-3.0902 * 10^{-3}$ & $-3.6262 * 10^{-7}$ & $1.0722 * 10^{-11}$ \\
\hline 58633 & 24.669 & $-3.5179 * 10^{-3}$ & $-2.0697 * 10^{-7}$ & $1.0246 * 10^{-12}$ \\
\hline 58725 & 25.240 & $-2.8282 * 10^{-3}$ & $-4.0218^{*} 10^{-7}$ & $1.2123 * 10^{-11}$ \\
\hline 58847 & 25.519 & $-3.1638 * 10^{-3}$ & $-3.5304 * 10^{-7}$ & $6.9978 * 10^{-12}$ \\
\hline 59134 & 26.547 & $-4.0034 * 10^{-3}$ & $-2.5330^{*} 10^{-7}$ & $5.0588 * 10^{-12}$ \\
\hline 59316 & 26.566 & $-4.2010^{-1} 10^{-3}$ & $-2.1264 * 10^{-7}$ & 5 \\
\hline
\end{tabular}

show the surface air pressure and the temperature distribution, respectively, for the Fujian province at 8 a.m. in May 30,2005 , generated by ordinary kriging interpolation in ArcGIS Desktop software.

\subsection{Three-Dimensional Interpolation}

The surface distribution maps of temperature and surface air pressure only reflect the distribution of the meteorological elements on the surface. Since real meteorological elements are distributed in three dimensions, the improvement of hail detection and other forecasts requires the establishment of three-dimensional meteorological element fields combining surface meteorological element and sounding data. For example, for the application of the WSR-88D Hail Detection Algorithm (HDA) it is vital to calculate the 0 and the $-20^{\circ} \mathrm{C}$ level height. Using traditional two-dimensional interpolation methods, we cannot acquire the threedimensional distribution features of the meteorological elements. As presented in the following sections, these are extended three-dimensionally according to the spatial distribution law of temperature and air pressure in the vertical direction.

In the troposphere, temperature decreases with height at a rate of about $6^{\circ} \mathrm{C} / 1000 \mathrm{~m}$. This rate varies with the season but can be calculated using the temperature change at different heights from the sounding data. According to the position of the sounding stations in or around the Fujian province, we divided the region into six parts using the Thiessen polygon method (Fig. 1). Then, the temperature data from the different sounding stations was fitted by cubic curves and lines, according to the parameters shown in Tables $\mathbf{1}$ and 2. From Fig. (4), we can see that the temperature lapse rate above the 
Table 2. Average temperature lapse rates for all sounding stations.

\begin{tabular}{|c|c|}
\hline Sounding Station & Temperature Lapse Rate \\
\hline \hline 57993 & -0.006382613 \\
\hline 58633 & -0.006311518 \\
\hline 58725 & -0.006421244 \\
\hline 58847 & -0.006438755 \\
\hline 59134 & -0.006430560 \\
\hline 59316 & -0.006347486 \\
\hline
\end{tabular}

Fujian province is roughly compatible with the rule, and that the fitted cubic curves are projected along the fitted lines. From Table 2 we can conclude a temperature decrease with height at a rate of about $6.4^{\circ} \mathrm{C} / 1000 \mathrm{~m}$ for that specific location and day.

According to the above temperature lapse rate at different locations, we extended the surface temperature distribution map to three dimensions. By adopting the fitted cubic curves, the three-dimensional temperature distribution map built with the OpenGL graphics program interface is shown in Fig. (5). The temperature sections can be acquired by moving the sliders in different heights and directions, and can be saved in a figure (.bmp) or text (.txt) format, to be used in the analysis of the temperature distribution characteristics at the height of hail formation.

The above method was used to extend the temperature field to three dimensions. To extend the air pressure three- dimensionally, we fitted the air pressure data from the different sounding stations to cubic curves and lines. From Fig. (6), we see that the air pressure lapse rate above the Fujian province was perfectly compatible with the cubic curve, whose parameters are shown in Table 3. Similarly, by adopting the fitted cubic curves, the three-dimensional air pressure distribution map was generated with the OpenGL graphics program interface (Fig. 7).

The air pressure sections can be acquired by moving the sliders in different heights and directions, and can be saved in a figure (.bmp) or text (.txt) format, to be used in the analysis of the air pressure distribution characteristics at the height of hail formation.

To verify the fitted pressure-altitude curve, we calculated the fitted heights using the following pressure-altitude equation:

$z_{2}-z_{1}=-R_{d} \int_{p_{1}}^{p_{2}} \frac{T_{v}}{g} d \ln p$

where $p 1$ and $p 2$ are the air pressure at two points, $z 1$ is the known height, and $z 2$ the unknown height. $R_{d}$ expresses the dry air gas constant $\left(287.05 \mathrm{~J} \cdot \mathrm{K}^{-1} \cdot \mathrm{kg}^{-1}\right)$ and $g$ is the gravity acceleration. $T v$ is the virtual temperature (in $\mathrm{K}$ ). Both $g$ and $T v$ vary with height, so it is very difficult to calculate an integral value. However, $g$ changes are very slow so that, for simplicity, a constant value of $9.785 \mathrm{~m} / \mathrm{s}^{2}$ is assumed according to the geographical position of the study area. The thermodynamic temperature $(T v)$ is given by the following equation:

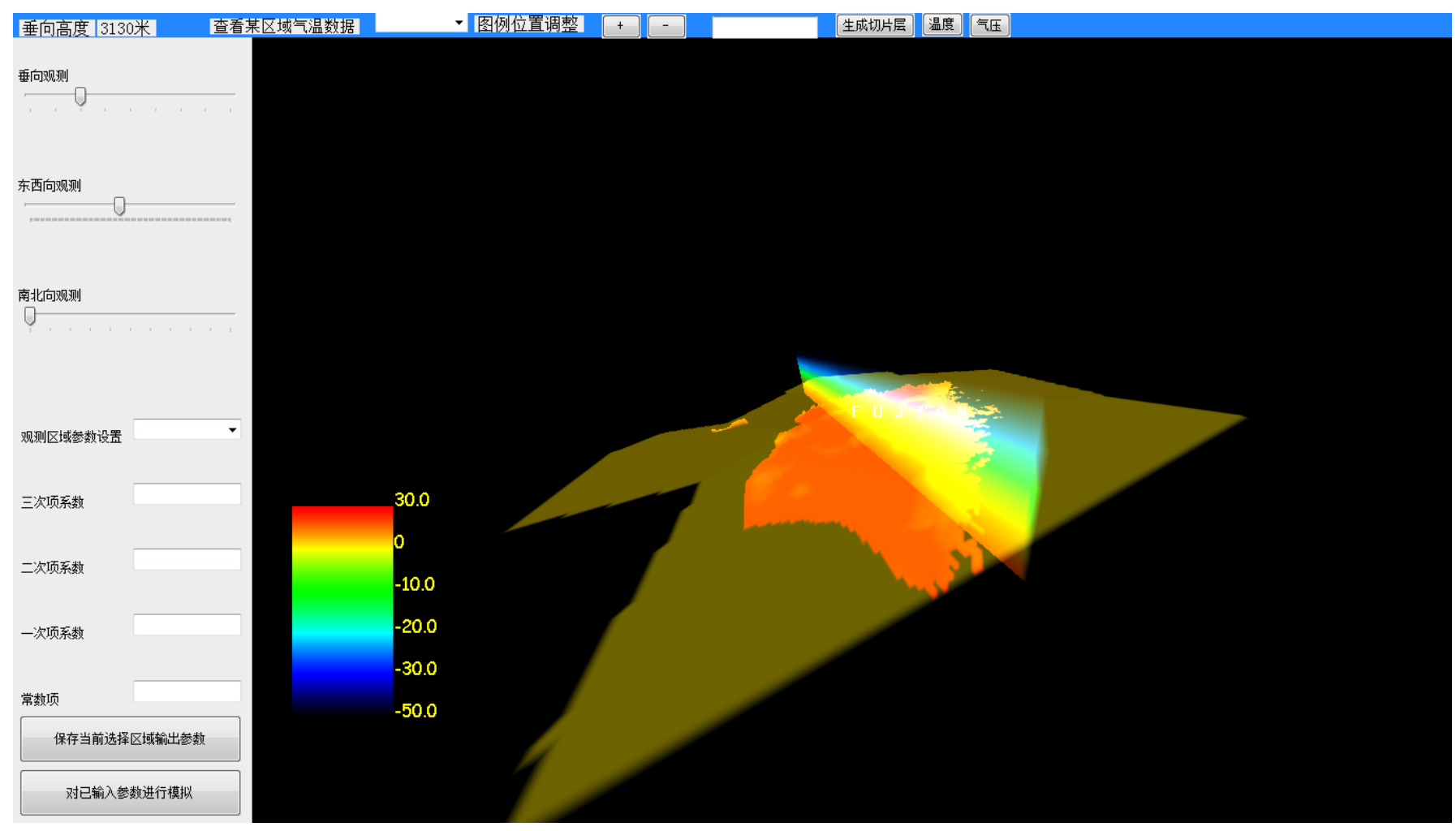

Fig. (5). Temperature distribution map $\left(\right.$ in $\left.^{\circ} \mathrm{C}\right)$ in three dimensions. 

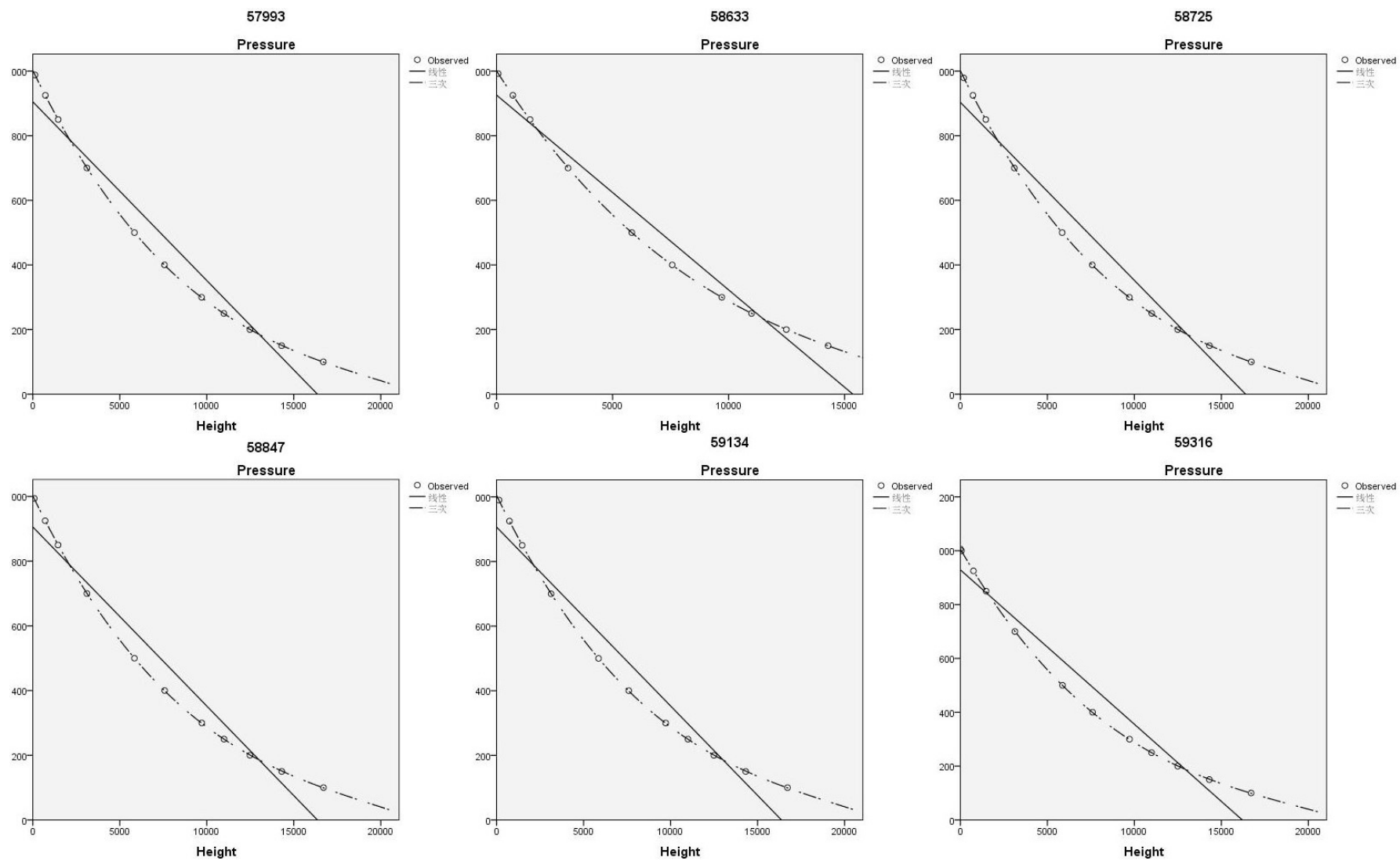

Fig. (6). Fitted air pressure lines and curves according to the height.

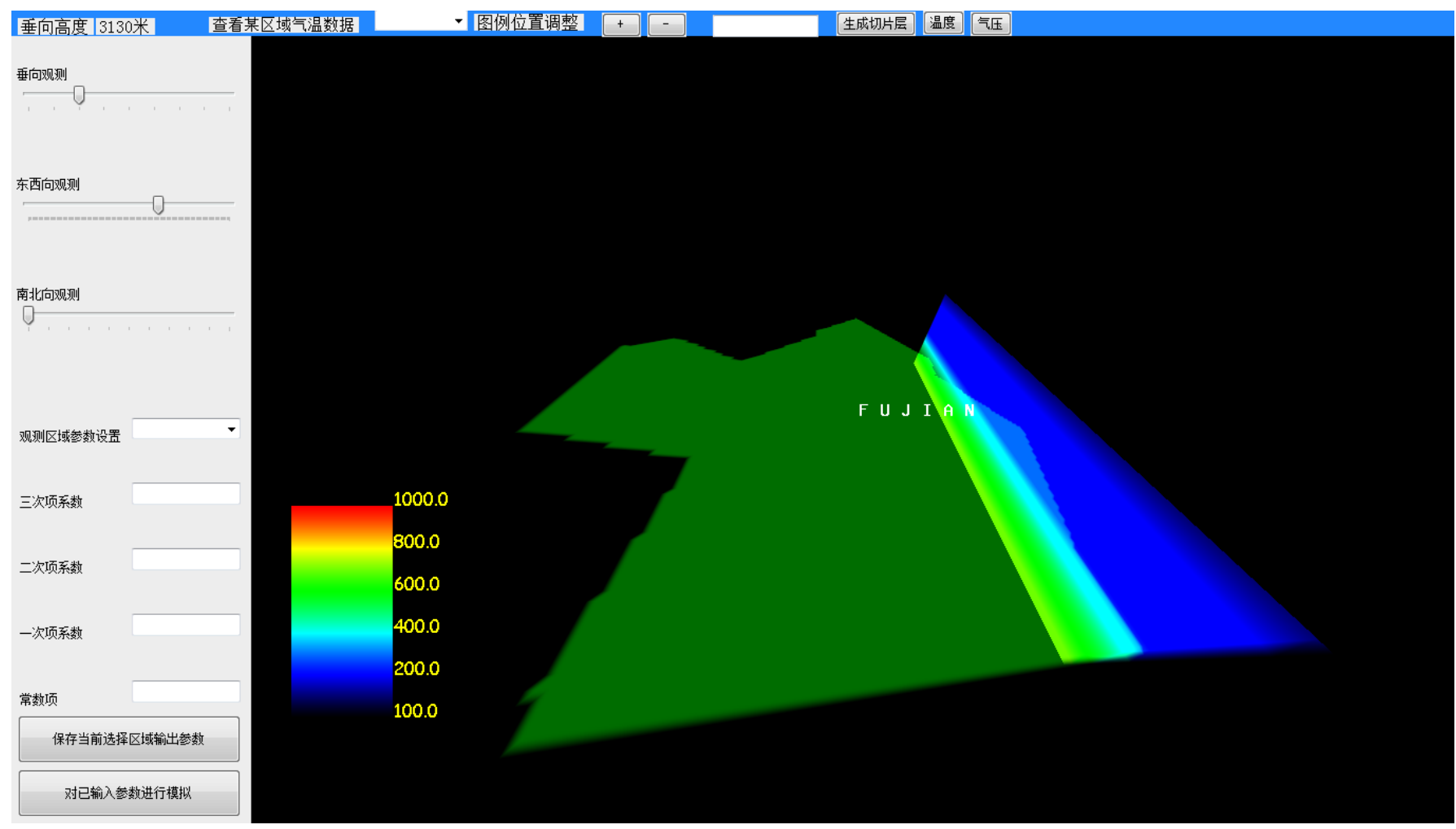

Fig. (7). Air pressure distribution map (in $\mathrm{hPa}$ ) in three dimensions. 
Table 3. Parameters of the fitted air pressure curves according to the height.

\begin{tabular}{|c|c|c|c|c|}
\hline Sounding Station & $\mathbf{c}$ & $\mathbf{x}$ & $\mathbf{x 2}$ & $\mathbf{x 3}$ \\
\hline \hline 57993 & 1001.704 & -0.1106 & $4.6875 * 10-6$ & $-7.7986 * 10-11$ \\
\hline 58633 & 1000.645 & -0.1117 & $4.9680 * 10-6$ & $-9.20564 * 10-11$ \\
\hline 58725 & 1001.489 & -0.1105 & $4.6987 * 10-6$ & $-7.8646 * 10-11$ \\
\hline 58847 & 1000.212 & -0.1100 & $4.6346 * 10-6$ & $-7.6461 * 10-11$ \\
\hline 59134 & 1003.223 & -0.1105 & $4.7501 * 10-6$ & $-7.6989 * 10-11$ \\
\hline 59316 & 1005.643 & -0.1113 & $-7.9879 * 10-11$ \\
\hline
\end{tabular}

$T_{v}=(1+0.622 \mathrm{q}) \mathrm{T}$

where $q$ expresses the specific humidity, calculated by the following equation:

$$
q=\frac{\varepsilon e}{p-0.378 e}
$$

where $e$ expresses the vapor pressure, calculated by the following equation:

$e= \begin{cases}6.1078 \exp \left[\frac{17.2693882(\mathrm{~T}-273.16)}{T-35.86}\right](\mathrm{T}>273.15) \\ 6.112 \exp \left[\frac{17.67(\mathrm{~T}-273.15)}{T-29.65}\right] & (\mathrm{T}<273.15)\end{cases}$ with $f$ representing the relative humidity, calculated by the following equation:

$f=\frac{e}{e} \approx q$$$
e_{s} \quad q_{s}
$$

Based on the above formulas, the calculations were performed using MATLAB software. Considering the sounding data from station 57993 as an example, there were 18 valid layers at 8 a.m. May 11, 2011 CST. The space between two neighboring valid layers was divided into 500 sections of equal distance, and the temperature and dew-point temperature were fixed between the sub-layers (i.e., isothermal atmosphere between the sub-layers). The barometric height for the isothermal atmosphere was given by the Laplace barometric height equation:

Table 4. The fitted and calculated heights and their errors at station 57993 (including 18 layers).

\begin{tabular}{|c|c|c|c|c|c|c|c|}
\hline $\begin{array}{c}\text { Air Pressure } \\
\qquad(\mathrm{hPa})\end{array}$ & $\begin{array}{c}\text { Observed } \\
\text { Altitude (m) }\end{array}$ & $\begin{array}{c}\text { Temperature } \\
\left({ }^{\circ} \mathrm{C}\right)\end{array}$ & $\begin{array}{c}\text { Dew-point } \\
\text { Temperature } \\
\left({ }^{\circ} \mathrm{C}\right)\end{array}$ & $\begin{array}{c}\text { Fitted } \\
\text { Height (m) }\end{array}$ & $\begin{array}{c}\text { Error of Fitted } \\
\text { Height (\%) }\end{array}$ & $\begin{array}{l}\text { Calculated } \\
\text { Height (m) }\end{array}$ & $\begin{array}{c}\text { Error of } \\
\text { Calculated } \\
\text { Height (\%) }\end{array}$ \\
\hline 988 & 125 & 29 & 23 & -320.41 & 356.33 & 125 & 0 \\
\hline 925 & 720 & 24 & 21 & 615.62 & 14.50 & 710.27 & 1.35 \\
\hline 876 & 9999 & 20 & 20 & 1255.19 & & 1186.33 & \\
\hline 850 & 1460 & 19 & 19 & 1570.42 & 7.56 & 1447.59 & 0.85 \\
\hline 700 & 3110 & 11 & 9 & 3223.33 & 3.64 & 3100.99 & 0.29 \\
\hline 691 & 9999 & 10 & 8 & 3320.69 & & 3209.32 & \\
\hline 611 & 9999 & 4 & 4 & 4223.35 & & 4225.83 & \\
\hline 551 & 9999 & -2 & -6 & 4978.09 & & 5060.07 & \\
\hline 500 & 5840 & -3 & -13 & 5701.34 & 2.37 & 5832.87 & 0.12 \\
\hline 446 & 9999 & -7 & -49 & 6574.34 & & 6732.26 & \\
\hline 400 & 7570 & -14 & -49 & 7423.81 & 1.93 & 7570.83 & 0.01 \\
\hline 377 & 9999 & -18 & -47 & 7890.34 & & 8017.57 & \\
\hline 365 & 9999 & -17 & -55 & 8145.73 & & 8260.18 & \\
\hline 300 & 9700 & -28 & -63 & 9685.47 & 0.15 & 9701.22 & 0.01 \\
\hline 287 & 9999 & -30 & -64 & 10027.57 & & 10018.5 & \\
\hline 250 & 10980 & -38 & -70 & 11069.32 & 0.81 & 10986.45 & 0.06 \\
\hline 220 & 9999 & -46 & -76 & 11992.32 & & 11852.97 & \\
\hline 200 & 12480 & -50 & -79 & 12648.97 & 1.35 & 12482.4 & 0.02 \\
\hline
\end{tabular}


Table 5. The fitted and calculated heights and their errors at station 58633 (including 17 layers).

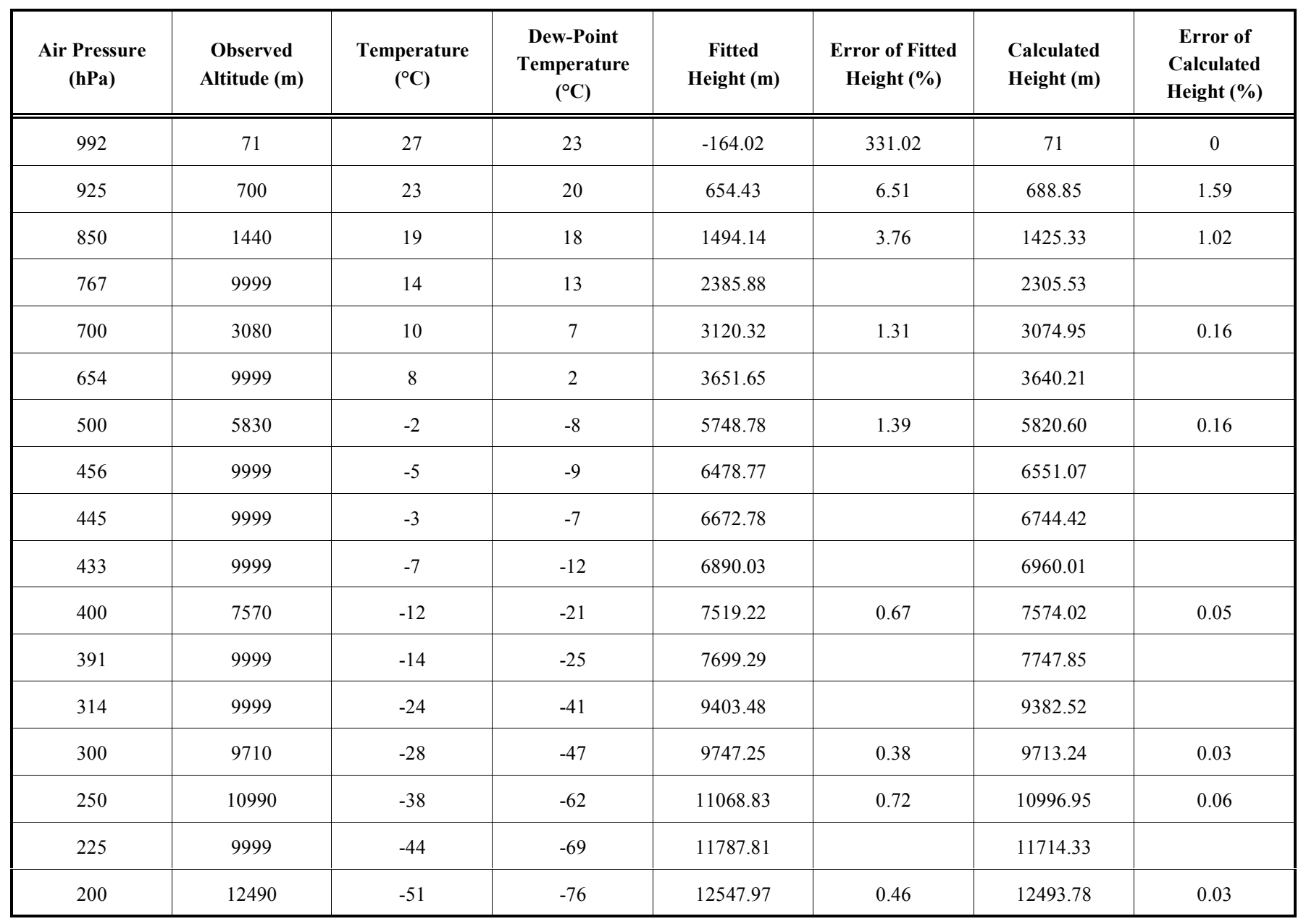

$z_{2}-z_{1}=\frac{R_{d} T_{v}}{g} \ln \frac{p_{1}}{p_{2}}$

According to the above method and formulas, we calculated the fitted and calculated height for different air pressures from the six sounding stations at 8 a.m. May 112011 CST, together with their associated error. The results are shown in Tables 4-9. If the cell value in these tables is "9999", the current observed value is missing.

\subsection{Error Analysis}

The errors of the fitted and calculated heights for the different sounding stations are shown in Tables 4-9. Their average errors were also calculated (Table 10). From Table 10, we conclude that (1) the error of the fitted height decreased at high altitude and increased at low altitude and (2) the error of the calculated height was always very low, and the calculated heights always fitted the observed values very well.

\subsection{Application of the Generation Methods}

The three-dimensional meteorological element maps generated by the above methods present the distribution characteristics of the meteorological elements at different heights. The two- and three-dimensional height maps for the 0 and $-20^{\circ} \mathrm{C}$ level at 8 a.m. May $11,2011 \mathrm{CST}$ generated by us are shown in Figs. (8) and (9). As the height of hailstone formation and development, is above the $0^{\circ} \mathrm{C}$ level height, these maps are very helpful for hail warning and forecasting. The extracted section of the temperature field shown in Fig. (10) plays a particularly important role in analyzing the atmosphere and accurately forecasting the weather.

\section{CONCLUSION}

The methods to interpolate the meteorological elements to two and three dimensions using sounding data from sounding stations and meteorological element data from automatic weather stations are discussed in this paper. The format and content of sounding and meteorological element data were introduced first, and then, using temperature and air pressure as examples, we extended the data to two and three dimensions and analyzed the error. The meteorological element distribution maps in two and three dimensions show high precision and reliability, playing an important role in hail warning and forecasting, by analyzing the atmosphere and accurately forecasting the weather. The addition of more types of meteorological data (like from national weather stations) in the future and the increase in the time resolution will further improve the quality of three-dimensional meteorological element fields. 
Table 6. The fitted and calculated heights and their errors at station 58725 (including 21 layers).

\begin{tabular}{|c|c|c|c|c|c|c|c|}
\hline $\begin{array}{l}\text { Air Pressure } \\
\text { (hPa) }\end{array}$ & $\begin{array}{c}\text { Observed } \\
\text { Altitude (m) }\end{array}$ & $\begin{array}{c}\text { Temperature } \\
\left({ }^{\circ} \mathrm{C}\right)\end{array}$ & $\begin{array}{c}\text { Dew-Point } \\
\text { Temperature } \\
\left({ }^{\circ} \mathrm{C}\right)\end{array}$ & $\begin{array}{c}\text { Fitted } \\
\text { Height (m) }\end{array}$ & $\begin{array}{c}\text { Error of Fitted } \\
\text { Height (\%) }\end{array}$ & $\begin{array}{l}\text { Calculated } \\
\text { Height (m) }\end{array}$ & $\begin{array}{c}\text { Error of } \\
\text { Calculated } \\
\text { Height }(\%)\end{array}$ \\
\hline 979 & 192 & 25 & 23 & -172.62 & 189.91 & 192 & 0 \\
\hline 971 & 9999 & 24 & 22 & -49.07 & & 264.41 & \\
\hline 955 & 9999 & 26 & 22 & 190.75 & & 411.26 & \\
\hline 925 & 720 & 25 & 20 & 616.20 & 14.42 & 693.73 & 3.65 \\
\hline 850 & 1460 & 19 & 17 & 1567.37 & 7.35 & 1432.47 & 1.89 \\
\hline 787 & 9999 & 15 & 14 & 2281.54 & & 2093.27 & \\
\hline 727 & 9999 & 13 & 10 & 2929.07 & & 2765.97 & \\
\hline 700 & 3100 & 11 & 8 & 3219.57 & 3.86 & 3084.49 & 0.5 \\
\hline 632 & 9999 & 5 & 4 & 3975.72 & & 3931.68 & \\
\hline 541 & 9999 & 1 & -8 & 5115.06 & & 5195.27 & \\
\hline 500 & 5850 & -3 & -16 & 5705.21 & 2.48 & 5825.55 & 0.42 \\
\hline 467 & 9999 & -6 & -28 & 6225.73 & & 6364.08 & \\
\hline 451 & 9999 & -8 & -23 & 6494.62 & & 6636.44 & \\
\hline 412 & 9999 & -10 & -51 & 7200.31 & & 7337.46 & \\
\hline 400 & 7580 & -12 & -52 & 7432.90 & 1.94 & 7564.78 & 0.2 \\
\hline 307 & 9999 & -26 & -61 & 9519.78 & & 9535.35 & \\
\hline 300 & 9710 & -28 & -63 & 9699.35 & 0.11 & 9701.90 & 0.08 \\
\hline 250 & 11000 & -38 & -70 & 11085.14 & 0.77 & 10985.55 & 0.13 \\
\hline 229 & 9999 & -43 & -70 & 11724.24 & & 11584.28 & \\
\hline 200 & 12490 & -51 & -74 & 12666.23 & 1.41 & 12482.24 & 0.06 \\
\hline 171 & 9999 & -58 & -81 & 13680.72 & & 13486.64 & \\
\hline
\end{tabular}

Table 7. The fitted and calculated heights and their errors at station 58847 (including 20 layers).

\begin{tabular}{|c|c|c|c|c|c|c|c|}
\hline $\begin{array}{l}\text { Air Pressure } \\
\text { (hPa) }\end{array}$ & $\begin{array}{c}\text { Observed } \\
\text { Altitud e(m) }\end{array}$ & $\begin{array}{c}\text { Temperature } \\
\left({ }^{\circ} \mathrm{C}\right)\end{array}$ & $\begin{array}{c}\text { Dew-Point } \\
\text { Temperature } \\
\left({ }^{\circ} \mathrm{C}\right)\end{array}$ & $\begin{array}{c}\text { Fitted } \\
\text { Height (m) }\end{array}$ & $\begin{array}{c}\text { Error of Fitted } \\
\text { Height (\%) }\end{array}$ & $\begin{array}{l}\text { Calculated } \\
\text { Height (m) }\end{array}$ & $\begin{array}{c}\text { Error of } \\
\text { Calculated } \\
\text { Height (\%) }\end{array}$ \\
\hline 994 & 85 & 26 & 24 & -431.94 & 608.16 & 85 & 0 \\
\hline 950 & 9999 & 22 & 21 & 249.10 & & 483.88 & \\
\hline 925 & 710 & 24 & 22 & 604.48 & 14.86 & 718.00 & 1.13 \\
\hline 919 & 9999 & 24 & 21 & 686.74 & & 775.33 & \\
\hline 850 & 1450 & 20 & 18 & 1562.59 & 7.77 & 1457.68 & 0.53 \\
\hline 700 & 3110 & 11 & 7 & 3221.39 & 3.58 & 3112.67 & 0.09 \\
\hline 645 & 9999 & 6 & 4 & 3829.16 & & 3792.15 & \\
\hline 576 & 9999 & 5 & -16 & 4654.85 & & 4719.39 & \\
\hline
\end{tabular}


Table 7. Contd.....

\begin{tabular}{|c|c|c|c|c|c|c|c|}
\hline $\begin{array}{l}\text { Air Pressure } \\
\text { (hPa) }\end{array}$ & $\begin{array}{c}\text { Observed } \\
\text { Altitud e(m) }\end{array}$ & $\begin{array}{c}\text { Temperature } \\
\left({ }^{\circ} \mathrm{C}\right)\end{array}$ & $\begin{array}{c}\text { Dew-Point } \\
\text { Temperature } \\
\left({ }^{\circ} \mathrm{C}\right)\end{array}$ & $\begin{array}{c}\text { Fitted } \\
\text { Height (m) }\end{array}$ & $\begin{array}{c}\text { Error of Fitted } \\
\text { Height }(\%)\end{array}$ & $\begin{array}{l}\text { Calculated } \\
\text { Height (m) }\end{array}$ & $\begin{array}{c}\text { Error of } \\
\text { Calculated } \\
\text { Height }(\%)\end{array}$ \\
\hline 522 & 9999 & -2 & -11 & 5382.13 & & 5513.56 & \\
\hline 503 & 9999 & -4 & -16 & 5660.3 & & 5807.87 & \\
\hline 501 & 9999 & -4 & -26 & 5690.34 & & 5839.35 & \\
\hline 500 & 5840 & -3 & -26 & 5705.42 & 2.30 & 5855.17 & 0.26 \\
\hline 482 & 9999 & -2 & -38 & 5983.38 & & 6146.37 & \\
\hline 400 & 7580 & -13 & -44 & 7430.00 & 1.98 & 7598.89 & 0.25 \\
\hline 366 & 9999 & -18 & -41 & 8130.88 & & 8270.31 & \\
\hline 300 & 9710 & -29 & -54 & 9693.09 & 0.17 & 9725.71 & 0.16 \\
\hline 278 & 9999 & -33 & -56 & 10279.38 & & 10266.7 & \\
\hline 250 & 10990 & -38 & -60 & 11077.39 & 0.80 & 11006.7 & 0.15 \\
\hline 211 & 9999 & -47 & -68 & 12291.9 & & 12153.67 & \\
\hline 200 & 12480 & -50 & -70 & 12657.3 & 1.42 & 12506.5 & 0.21 \\
\hline
\end{tabular}

Table 8. The fitted and calculated heights and their errors at station 59134 (including 20 layers).

\begin{tabular}{|c|c|c|c|c|c|c|c|}
\hline $\begin{array}{c}\text { Air Pressure } \\
\text { (hPa) }\end{array}$ & $\begin{array}{c}\text { Observed } \\
\text { Altitude (m) }\end{array}$ & $\begin{array}{c}\text { Temperature } \\
\left({ }^{\circ} \mathrm{C}\right)\end{array}$ & $\begin{array}{c}\text { Dew-Point } \\
\text { Temperature } \\
\left({ }^{\circ} \mathbf{C}\right)\end{array}$ & $\begin{array}{c}\text { Fitted } \\
\text { Height (m) }\end{array}$ & $\begin{array}{c}\text { Error of Fitted } \\
\text { Height }(\%)\end{array}$ & $\begin{array}{l}\text { Calculated } \\
\text { Height (m) }\end{array}$ & $\begin{array}{c}\text { Error of } \\
\text { Calculated } \\
\text { Height (\%) }\end{array}$ \\
\hline 990 & 139 & 26 & 23 & -337.46 & 342.78 & 139 & 0 \\
\hline 925 & 740 & 24 & 20 & 631.31 & 14.69 & 739.05 & 0.13 \\
\hline 850 & 1470 & 20 & 16 & 1587.00 & 7.96 & 1477.62 & 0.52 \\
\hline 836 & 9999 & 21 & 15 & 1751.36 & & 1621.83 & \\
\hline 700 & 3130 & 11 & 8 & 3242.18 & 3.58 & 3137.24 & 0.23 \\
\hline 616 & 9999 & 3 & -1 & 4184.22 & & 4192.30 & \\
\hline 605 & 9999 & 5 & -9 & 4315.31 & & 4339.19 & \\
\hline 500 & 5860 & -5 & -12 & 5722.74 & 2.34 & 5868.65 & 0.15 \\
\hline 497 & 9999 & -5 & -14 & 5768.15 & & 5916.07 & \\
\hline 492 & 9999 & -5 & -30 & 5844.59 & & 5995.68 & \\
\hline 479 & 9999 & -5 & -47 & 6047.94 & & 6206.36 & \\
\hline 475 & 9999 & -4 & -47 & 6111.88 & & 6272.46 & \\
\hline 400 & 7600 & -14 & -53 & 7445.63 & 2.03 & 7603.48 & 0.05 \\
\hline 358 & 9999 & -19 & -57 & 8320.39 & & 8438.57 & \\
\hline 300 & 9720 & -30 & -64 & 9706.76 & 0.14 & 9727.03 & 0.07 \\
\hline 270 & 9999 & -36 & -69 & 10514.33 & & 10469.13 & \\
\hline 250 & 11000 & -38 & -70 & 11089.9 & 0.82 & 11002.27 & 0.02 \\
\hline
\end{tabular}


Table 8. Contd......

\begin{tabular}{|c|c|c|c|c|c|c|c|}
\hline $\begin{array}{c}\text { Air Pressure } \\
(\mathbf{h P a})\end{array}$ & $\begin{array}{c}\text { Observed } \\
\text { Altitude (m) }\end{array}$ & $\begin{array}{c}\text { Temperature } \\
\left({ }^{\circ} \mathbf{C}\right)\end{array}$ & $\begin{array}{c}\text { Dew-Point } \\
\text { Temperature } \\
\left({ }^{\circ} \mathbf{C}\right)\end{array}$ & $\begin{array}{c}\text { Fitted } \\
\text { Height (m) }\end{array}$ & $\begin{array}{c}\text { Error of Fitted } \\
\text { Height (\%) }\end{array}$ & $\begin{array}{c}\text { Calculated } \\
\text { Height (m) }\end{array}$ & $\begin{array}{c}\text { Error of } \\
\text { Calculated } \\
\text { Height (\%) }\end{array}$ \\
\hline \hline 232 & 9999 & -42 & -73 & 11634.62 & & 11513.3 & 12501.88 \\
\hline 200 & 12490 & -50 & -79 & 12668.49 & 1.43 & 13622.19 & 0.10 \\
\hline 168 & 9999 & -58 & -84 & 13790.72 & & \\
\hline
\end{tabular}

Table 9. The fitted and calculated heights and their errors at station 59316 (including 19 layers).

\begin{tabular}{|c|c|c|c|c|c|c|c|}
\hline $\begin{array}{l}\text { Air Pressure } \\
\quad(\mathrm{hPa})\end{array}$ & $\begin{array}{c}\text { Observed } \\
\text { Altitude (m) }\end{array}$ & $\begin{array}{c}\text { Temperature } \\
\left({ }^{\circ} \mathrm{C}\right)\end{array}$ & $\begin{array}{c}\text { Dew-Point } \\
\text { Temperature } \\
\left({ }^{\circ} \mathrm{C}\right)\end{array}$ & $\begin{array}{c}\text { Fitted } \\
\text { Height (m) }\end{array}$ & $\begin{array}{c}\text { Error of Fitted } \\
\text { Height (\%) }\end{array}$ & $\begin{array}{l}\text { Calculated } \\
\text { Height (m) }\end{array}$ & $\begin{array}{c}\text { Error of } \\
\text { Calculated } \\
\text { Height (\%) }\end{array}$ \\
\hline 1006 & 3 & 28 & 24 & -151.81 & 5160.42 & 3 & 0 \\
\hline 1000 & 60 & 27 & 21 & -73.42 & 222.37 & 56.31 & 6.15 \\
\hline 925 & 750 & 23 & 20 & 829.98 & 10.66 & 744.68 & 0.71 \\
\hline 850 & 1480 & 20 & 17 & 1630.87 & 10.19 & 1482.22 & 0.15 \\
\hline 700 & 3130 & 10 & 9 & 3151.11 & 6.74 & 3134.60 & 0.15 \\
\hline 671 & 9999 & 8 & 6 & 3461.92 & & 3486.82 & \\
\hline 615 & 9999 & 6 & 1 & 4102.55 & & 4206.32 & \\
\hline 546 & 9999 & 0 & -5 & 4994.86 & & 5173.5 & \\
\hline 513 & 9999 & -3 & -17 & 5473.67 & & 5671.26 & \\
\hline 500 & 5870 & -4 & -16 & 5673.07 & 3.35 & 5874.55 & 0.08 \\
\hline 469 & 9999 & -8 & -25 & 6175.51 & & 6376.61 & \\
\hline 461 & 9999 & -8 & -49 & 6311.70 & & 6510.46 & \\
\hline 440 & 9999 & -8 & -49 & 6682.73 & & 6873.14 & \\
\hline 400 & 7600 & -14 & -53 & 7447.52 & 2.01 & 7606.01 & 0.08 \\
\hline 300 & 9720 & -30 & -64 & 9742.85 & 0.24 & 9722.38 & 0.02 \\
\hline 268 & 9999 & -37 & -69 & 10609.24 & & 10515.16 & \\
\hline 250 & 10990 & -39 & -71 & 11127.7 & 1.25 & 10994.75 & 0.04 \\
\hline 238 & 9999 & -41 & -72 & 11486.28 & & 11331.18 & \\
\hline 200 & 12490 & -49 & -78 & 12692.99 & 1.63 & 12494.85 & 0.04 \\
\hline
\end{tabular}

Table 10. Average errors of the fitted and calculated heights.

\begin{tabular}{|c|c|c|c|c|c|c|}
\hline Sounding Station & $\mathbf{5 7 9 9 3}$ & $\mathbf{5 8 6 3 3}$ & $\mathbf{5 8 7 2 5}$ & $\mathbf{5 8 8 4 7}$ & $\mathbf{5 9 1 3 4}$ & $\mathbf{5 9 1 3 6}$ \\
\hline \hline A & 4.04 & 1.90 & 4.04 & 4.11 & 4.12 & 4.51 \\
\hline B & 0.30 & 0.34 & 0.77 & 0.31 & 0.14 & 0.82 \\
\hline
\end{tabular}

A: Average Error of Fitted Height $(\%$, Height $>700 \mathrm{~m})$

B: Average Error of Calculated Height (\%) 


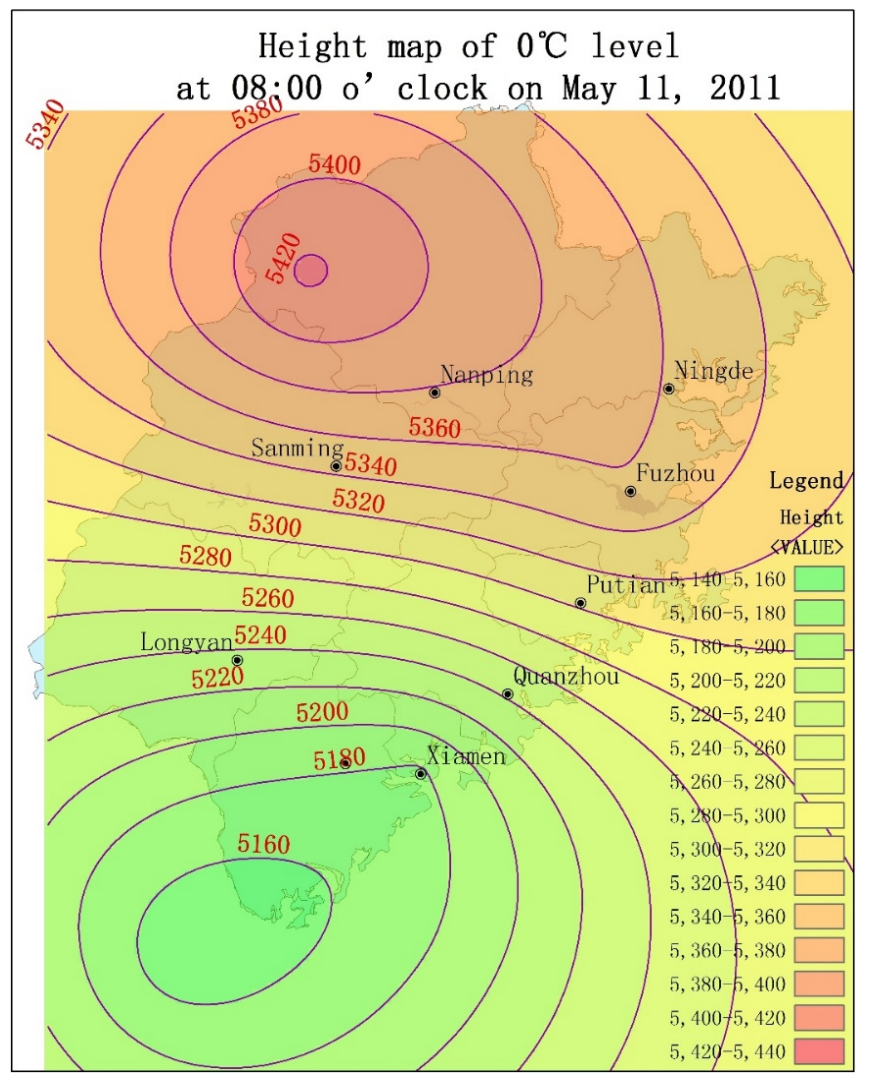

Fig. (8). Height map (in m) of $0^{\circ} \mathrm{C}$ level at 8 a.m. May 11, 2011.

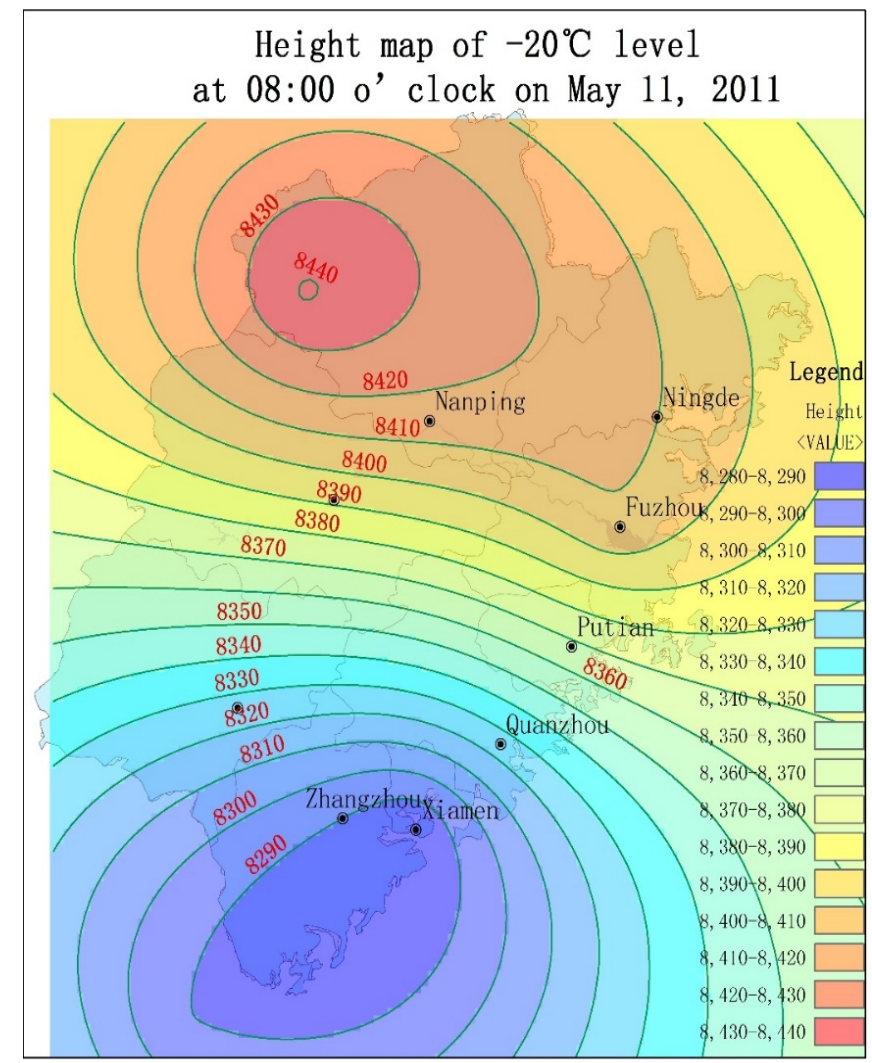

Fig. (9). Height map (in m) of $-20^{\circ} \mathrm{C}$ level at 8 a.m. May 11, 2011.

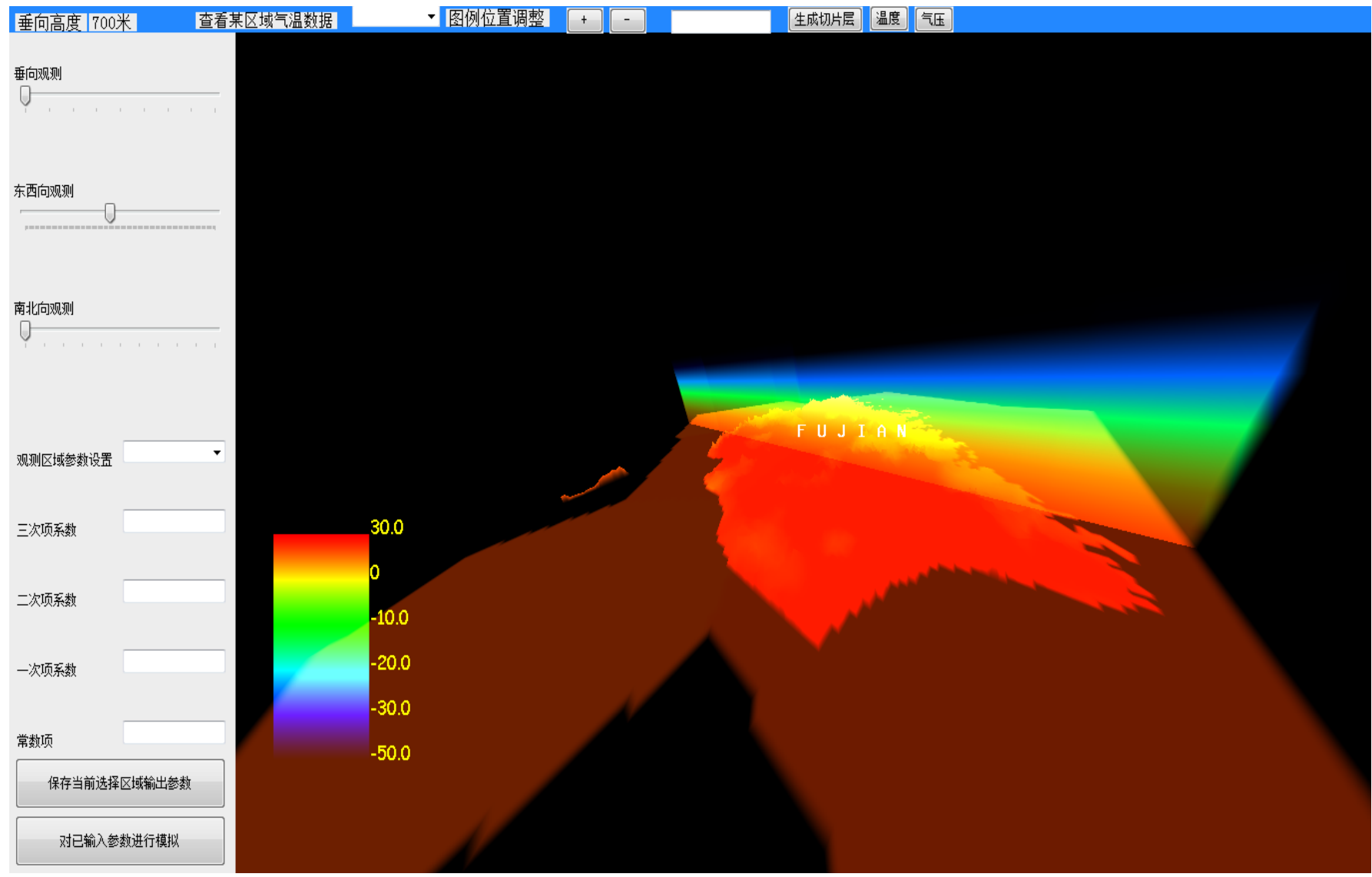

Fig. (10). Temperature section $\left(\right.$ in $\left.^{\circ} \mathrm{C}\right)$ at 8 a.m. May 11, 2011. 


\section{CONFLICT OF INTEREST}

The authors confirm that this article content has no conflict of interest.

\section{ACKNOWLEDGEMENTS}

The research reported herein was sponsored by the National Science and Technology Major Project of China (Grant No. 2011ZX05039-004), the National Science and Technology Support Program of China (Grant No. 2012BAC25B01) and the Scientific Research Foundation for Doctor of Shijiazhuang Tiedao University.

\section{REFERENCES}

[1] S. J. Jeffrey, J. O. Carter, K. B. Moodie, and A. R. Beswick, "Using spatial interpolation to construct a comprehensive archive of Australian climate data," Environmental Modelling and Software, vol. 16, no. 4, pp. 309-330, 2001.

[2] Z. H. Lin, X. G. Mo, H. X. Li, and H. B. Li, "Comparison of three spatial interpolation methods for climate variables in China", Acta Geographica Sinica, (In Chinese) vol. 57, no. 1, pp. 47-56, 2002
[3] Z. M. Feng, Y. Z. Yang, X. Q. Ding and Z. H. Lin, "Optimization of the spatial interpolation methods for climate resources", Geographical Research, vol. 23, no. 3, pp. 357-364, 2004. (In Chinese).

[4] F. Cai, G. R. Yu, Q. L. Zhu, H. L. He, X. A. Liu, Z. Q. Li and X. B. Guo, "Comparison of precisions between spatial methods of climatic factors: a case study on mean air temperature", Resources Science, vol. 27, no. 5, pp 173-179, 2005. (In Chinese).

[5] J. L. Li, J. Zhang, C. Zhang and Q. G. Chen, "Analyze and compare the spatial interpolation methods for climate factor", Pratacultural Science, vol. 23, no. 8, pp. 6-11, 2006. (In Chinese).

[6] X. L. Ma, C. E. Li, and Q. G. Chen, "Study on the method of GIS based spatial interpolation of climate factors in China", Pratacultural Science, vol. 25, no. 11, pp. 13-19, 2008. (In Chinese).

[7] X. J. Jiang, X. J. Liu, F. Huang, H. Y. Jiang, W. X. Cao, and Y. Zhu, "Comparison of spatial interpolation methods for daily meteorological elements", Chinese Journal of Applied Ecology, vol. 21, no. 3, pp. 624-630, 2010. (In Chinese).

[8] C. Tobin, L. Nicotina, M. B. Parlange, A. Berne, and A. Rinaldo "Improved interpolation of meteorological forcings for hydrologic applications in a Swiss Alpine region", Journal of Hydrology, vol. 401no. 1-2, pp. 77-89, 2011

[9] T. Wu, and Y. Li "Spatial interpolation of temperature in the United States using residual kriging", Applied Geography, vol. 44, pp. 112-120, 2013

Received: September 16, 2014

Revised: December 23, 2014

Accepted: December 31, 2014

(C) Yu et al.; Licensee Bentham Open.

This is an open access article licensed under the terms of the Creative Commons Attribution Non-Commercial License (http://creativecommons.org/licenses/by-nc/3.0/) which permits unrestricted, non-commercial use, distribution and reproduction in any medium, provided the work is properly cited. 